\title{
Analisis Deskriptif Pemain Online Game pada Game Defense of the Ancients 2 (Dota 2)
}

\author{
Maddarangan, I. F., Nuzulfah, V., dan Wibawa, B. M. \\ Departemen Manajemen Bisnis, Fakultas Bisnis dan Manajemen Teknologi, \\ Institut Teknologi Sepuluh Nopember (ITS) \\ e-mail: berto@mb.its.ac.id
}

\begin{abstract}
Abstrak-Pertumbuhan Industri Game Indonesia semakin meningkat tiap tahunnya. Tujuan dari penelitian ini adalah mengidentifikasi karakteristik demografis pemain online game Defense Of The Ancients 2 (DOTA 2). Penelitian ini menggunakan pendekatan deskriptif-konklusif dengan menggunakan pengumpulan data yang bersifat multi crosssectional. Data penelitian ini diperoleh menggunakan survei kuesioner yang disebar di Surabaya dan menghasilkan 667 responden pemain berbayar dan 163 responden pemain tidak berbayar. Hasil dari penelitian ini menunjukkan karakteristik demografi yang ada pada pemain dalam online game DOTA 2.
\end{abstract}

Kata Kunci-Online Game, DOTA 2, Demografi.

\section{PENDAHULUAN}

$P^{\prime}$ ERTUMBUHAN industri game diprediksi akan bertumbuh di masa yang akan datang. Pertumbuhan pasar industri game diprediksi akan mengalami pertumbuhan positif secara global hingga tahun 2020 hingga menyentuh angka USD 90 Milyar [1].

Salah satu wilayah yang berkontribusi besar dalam pertumbuhan pasar global tersebut adalah wilayah Asia Pasifik [2]. Indonesia yang termasuk dalam wilayah Asia Pasifik adalah negara dengan pertumbuhan industri game kedua setelah Thailand [3]. Berdasarkan Ketua Asosiasi Game Indonesia (AGI), pertumbuhan pasar industri game Indonesia didominasi oleh pertumbuhan dari game PC dan mobile game [4]. Dengan kata lain, dapat disimpulkan bahwa pasar industri game di Indonesia memiliki potensi yang cukup besar untuk diperhatikan selanjutnya.

Salah satu dampak yang memengaruhi perkembangan pasar industri game adalah persaingan antar developer game itu sendiri. Untuk saat ini, developer game yang mendominasi pasar game adalah Valve yang dibangun oleh Gabe Newal dan Mike Harrington pada tahun 1996 [5]. Perusahaan game tersebut memiliki beberapa game yang terkenal yaitu Defense of the Ancients 2 (DOTA 2), Counter Strike Global Offensive, dan Paladins. Salah satu game Valve yang paling dikenal saat ini adalah DOTA 2. DOTA 2 memiliki jumlah pemain yang tergolong cukup besar di Indonesia yaitu 3.462 .626 pemain [6]. Rata-rata waktu bermain DOTA 2 mencapai sekitar 12 jam per minggu yang mengalahkan game lain yang dibuat oleh Valve.

Mengingat ketatnya persaingan antar developer game, pertumbuhan pendapatan online game merupakan hal penting yang perlu diperhatikan oleh developer game. Pemain game yang menyukai permainan yang dimainkannya rela mengeluarkan uang demi game yang disukainya [7]. Maka dari itu, developer game berlombalomba mendapatkan tambahan pendapatan dalam industri game itu sendiri.

Perkembangan industri game tidak hanya menarik perhatian developer game. Investor juga menjadi tertarik mengingat bahwa pertumbuhan industri game secara global maupun di Indonesia memiliki potensi yang besar. Salah satu penyebab pertumbuhan pasar online game adalah penjualan virtual item. Oleh karena itu, minat pembelian dari pemain online game merupakan hal yang penting untuk diperhatikan agar dapat meningkatkan pendapatan game itu sendiri.

Meneliti mengenai penjualan virtual item menjadi hal yang penting. Penelitian dari Park dan Lee (2011) menemukan bahwa faktor yang memengaruhi minat pembelian adalah kepuasan, identifikasi karakter, nilai integrasi, kompetensi karakter, otoritas visual dan hal moneter [8]. Penelitian yang dilakukan Hsiao dan Cheng juga menyatakan bahwa faktor yang memengaruhi minat pembelian dalam mobile game yaitu harga yang bagus, hadiah, dan loyalitas [9]. Maka dari itu, penelitian ini berfokus pada beberapa aspek yaitu pertumbuhan pemain online game di Indonesia yang semakin meningkat dan besarnya pertumbuhan pasar dalam online game.

\section{TINJAUAN PUSTAKA}

Online game adalah komponen-komponen penting pada online game yang terdiri dari pemain game anak-anak, remaja, dan dewasa [10]. Online game juga merupakan pemainan yang menggunakan jaringan internet [11]. Aktivitas dalam online game merupakan hiburan dari memainkan game tersebut [12]. Salah satu online game yang sedang populer di masa ini adalah DOTA 2. DOTA 2 merupakan permainan online game yang terdiri dari 1-10 pemain yang terbagi menjadi dua kelompok [13]. DOTA 2 memiliki tujuan permainan untuk menghancurkan markas lawan atau ancients musuh [13].

\section{METODOLOGI PENELITIAN}

\section{A. Jenis Data}

Data primer merupakan data karakteristik demografi responden yang diperoleh menggunakan metode survei kuesioner pada responden yang dianggap telah mewakili sampel dari populasi penelitian [14]. Data yang diambil adalah data kuesioner penelitian dalam demografi responden.

\section{B. Pengumpulan Data}

Penelitian dilakukan dengan menggunakan metode survei melalui kuesioner yang disebar secara online [15]. Populasi dalam penelitian ini adalah seluruh mahasiswa pemain online game di Surabaya. Peneliti mengambil sampel dari populasi tersebut menggunakan teknik pengambilan sampel non-probability sampling [16]. Metode pengambilan sampel yang digunakan adalah convenience 
Tabel 1.

Deskriptif Demografi Responden

\begin{tabular}{|c|c|c|}
\hline Profil & Frekuensi & Persentase $(\%)$ \\
\hline \multicolumn{3}{|l|}{ Jenis Kelamin } \\
\hline Laki-laki & 803 & 96,7 \\
\hline Perempuan & 27 & 3,3 \\
\hline Total & 830 & 100,0 \\
\hline \multicolumn{3}{|l|}{ Usia } \\
\hline 16-18 tahun & 101 & 12,2 \\
\hline 19-20 tahun & 345 & 41,6 \\
\hline $21-22$ tahun & 302 & 36,4 \\
\hline 23-24 tahun & 65 & 7,8 \\
\hline$>25$ tahun & 17 & 2,0 \\
\hline Total & 830 & 100,0 \\
\hline \multicolumn{3}{|l|}{ Status Penikahan } \\
\hline Sudah menikah & 10 & 1,2 \\
\hline Belum menikah & 813 & 98,0 \\
\hline $\begin{array}{l}\text { Pernah menikah } \\
\text { (Janda/Duda) }\end{array}$ & 7 & 0,8 \\
\hline Total & 830 & 100,0 \\
\hline \multicolumn{3}{|c|}{ Daerah Tempat Tinggal } \\
\hline Surabaya pusat & 38 & 4,6 \\
\hline Surabaya utara & 48 & 5,8 \\
\hline Surabaya timur & 517 & 62,3 \\
\hline Surabaya selatan & 160 & 19,3 \\
\hline Surabaya barat & 67 & 8,1 \\
\hline Total & 830 & 100,0 \\
\hline \multicolumn{3}{|l|}{ Pendapatan } \\
\hline <Rp. 1.000 .000 & 449 & 54,1 \\
\hline $\begin{array}{l}\text { Rp. 1.000.001-Rp. } \\
1.500 .000\end{array}$ & 181 & 21,8 \\
\hline $\begin{array}{l}\text { Rp. 1.500.001-Rp. } \\
2.000 .000\end{array}$ & 93 & 11,2 \\
\hline$>$ Rp. 2.000 .000 & 107 & 12,9 \\
\hline Total & 830 & 100,0 \\
\hline
\end{tabular}

Tabel 1

Deskriptif Demografi Responden (Lanjutan)

\begin{tabular}{lrr}
\hline \hline \multicolumn{1}{c}{ Profil } & Frekuensi & \multicolumn{2}{c}{ Persentase (\%) } \\
\hline Pengeluaran Virtual Item & & \\
<Rp. 50.000 & 361 & 43,5 \\
Rp. 50.001-Rp. 100.000 & 196 & 23,6 \\
Rp. 100.001-Rp. 200.000 & 131 & 15,8 \\
>Rp. 200.000 & 142 & 17,1 \\
\hline Total & 830 & 100,0 \\
\hline \hline
\end{tabular}

sampling. Terdapat 830 kuesioner yang diperoleh setelah penyebarakan kuesioner dari bulan Mei 2017 hingga Juni 2017. Analisis yang digunakan dalam penelitian ini merupakan analisis deskriptif terhadap demografi responden [17].

\section{ANALISIS DAN PEMBAHASAN}

\section{A. Analisis Deskriptif}

Analisis deskriptif demografi dan usage dilakukan dalam penelitian ini untuk mengetahui karakteristik demografi responden dan penggunaan mengenai online game DOTA 2. Berikut adalah hasil analisis demografi pemain online game DOTA 2 pada Tabel 1.
Tabel 2

Deskriptif Usage Responden

\begin{tabular}{lrr}
\hline \hline \multicolumn{1}{c}{ Profil } & Frekuensi & Persentase (\%) \\
\hline Lama bermain DOTA2 & & \\
1 tahun & 123 & 14,8 \\
2 tahun & 128 & 15,4 \\
$>2$ tahun & 503 & 60,6 \\
\hline Total & 830 & 100,0 \\
\hline Rata-rata waktu main & 148 & 17,8 \\
<5 jam & 83 & 10,0 \\
5 jam & 72 & 8,7 \\
6 jam & 527 & 63,5 \\
$>6$ jam & 830 & 100,0 \\
\hline Total & & \\
\hline Rata-rata match & 129 & 15,5 \\
<5 match & 269 & 32,5 \\
6-10 match & 158 & 19,0 \\
11-15 match & 274 & 33,0 \\
$>15$ match & 830 & 100,0 \\
\hline Total & & \\
\hline Tipe pemain & 667 & 19,6 \\
Pemain berbayar & 163 & 100,0 \\
Pemain tidak berbayar & 830 & \\
\hline Total & & \\
\hline \hline
\end{tabular}

Mayoritas responden dalam penelitian ini adalah lakilaki dengan mayoritas kategori kelompok usia 19-20 tahun dan 21-22 tahun. Status pernikahan didominasi oleh belum menikah sebanyak 98 persen. Daerah tempat tinggal kebanyakan berada pada daerah Surabaya Timur sebesar 62,3 persen. Terdapat 54,1 persen responden memiliki pendapatan diatas kurang dari Rp.1.000.000,00.

Untuk pengeluaran virtual item, sebanyak 43,5 persen mengeluarkan kurang dari Rp. 50.000,00 tiap 3 bulan dan 23,2 persen mengeluarkan Rp. 50.001,00 - Rp. 100.000,00 tiap 3 bulan.

Lama memainkan online game DOTA 2 didominasi oleh pemain yag telah bermain lebih dari 2 tahun. Rata-rata waktu memainkan online game DOTA 2 per minggu kebanyakan lebih dari 6 jam sebesar 63,6 persen. Rata-rata match DOTA 2 yang dilakukan sekali seminggu adalah lebih dari 15 match dan 6-10 match. Tipe pemain dalam responden ini terbagi dua yaitu, pemain berbayar sebesar 80,4 persen dan pemain tidak berbayar sebesar 19,6 persen. Asal mengenal online game DOTA 2 adalah dari teman sendiri sebesar 79,7 persen. Untuk device yang digunakan dalam memainkan DOTA 2 didominasi oleh Laptop sebanyak 68 persen dan Desktop PC sebesar 32 persen. Pemain online game DOTA 2 yang menggunakan aplikasi steam mobile sebanyak 77,5 persen. Tempat memainkan online game DOTA 2 adalah di rumah sebanyak 68,4 persen dan warnet 16,6 persen. (Tabel 2)

Solo MMR 2.001-3.000 sebanyak 26,6 persen, Solo MMR 1.001-2.000 sebanyak 20,7 persen, dan Solo MMR 3.001-4000 sebanyak 19,9 persen. Untuk alasan memainkan online game DOTA 2 kebanyakan berasal dari alasan kerja sama teman, desain permainan dan grafik permainan dalam online game DOTA 2 itu sendiri. Metode pembayaran yang disukai oleh responden penelitian adalah pihak ketiga (forum jual beli, online shop, teman) sebesar 55,9 persen dan metode pembayaran voucher sebesar 33,5 persen.

Peran online game DOTA 2 yang sering dimainkan adalah peran support sebanyak 39,2 persen, peran midlaner sebanyak 29,5 persen, peran roaming sebanyak 20,2 persen, dan peran tanker sebanyak 11,1 persen. 
Tabel 2

Deskriptif Usage Responden (Lanjutan)

\begin{tabular}{|c|c|c|}
\hline Profil & Frekuensi & $\begin{array}{c}\text { Persentase } \\
(\%)\end{array}$ \\
\hline \multicolumn{3}{|c|}{ Asal mengenal online game DOTA 2} \\
\hline Teman & 662 & 79,7 \\
\hline Keluarga & 82 & 9,9 \\
\hline Media sosial & 29 & 3,5 \\
\hline Iklan/T urnamen & 25 & 3,0 \\
\hline Lainnya & 31 & 3,9 \\
\hline Total & 830 & 100,0 \\
\hline \multicolumn{3}{|l|}{ Device } \\
\hline Desktop PC & 266 & 32,0 \\
\hline Laptop & 564 & 68,0 \\
\hline Total & 830 & 100,0 \\
\hline \multicolumn{3}{|l|}{ Pengguna steam mobile } \\
\hline Pemain dengan steam mobile & 643 & 77,5 \\
\hline Pemain tanpa steam mobile & 187 & 22,5 \\
\hline Total & 830 & 100,0 \\
\hline \multicolumn{3}{|l|}{ Tempat bermain } \\
\hline Rumah & 568 & 68,4 \\
\hline Warnet & 138 & 16,6 \\
\hline Gamecenter & 36 & 4,4 \\
\hline Lainnya & 88 & 10,6 \\
\hline Total & 830 & 100,0 \\
\hline \multicolumn{3}{|l|}{ Solo MMR } \\
\hline Tidak ada & 115 & 13,9 \\
\hline$<1.000$ & 47 & 5,7 \\
\hline $1.001-2.000$ & 172 & 20,7 \\
\hline $2.001-3.000$ & 221 & 26,6 \\
\hline $3.001-4.000$ & 165 & 19,9 \\
\hline$>4.000$ & 110 & 13,3 \\
\hline Total & 830 & 100,0 \\
\hline
\end{tabular}

\section{KESIMPULAN}

\section{A. Kesimpulan}

Analisis deksriptif demografi dalam penelitian ini menunjukkan bahwa pemain online game DOTA 2 didominasi oleh laki-laki, karena permainan ini tergolong pertandingan karakter game. Kelompok usia dalam penelitian ini kebanyakan adalah kategori 19-20 tahun dan 21-22 tahun, karena responden penelitian adalah mahasiswa. Secara umum, tingkat pendapatan responden masuk dalam kategori menengah ke bawah, karena rata-rata mahasiswa dalam responden ini belum memiliki pekerjaan. Sehingga, pengeluaran untuk virtual item game juga tidak tergolong cukup besar.

Analisis deskriptif usage memiliki hasil bahwa lama pemain telah memainkan online game DOTA 2 didominasi oleh pemain yang telah memainkan online game DOTA 2 lebih dari 2 tahun dan waktu main tiap minggunya mencapai lebih dari 6 jam. Match yang biasa dilakukan lebih dari 15 kali. Selain itu, tipe pemain terbesar dalam online game DOTA 2 di Surabaya adalah pemain berbayar sebanyak 667 orang. Metode pembayaran yang disukai responden adalah pihak ketiga dan voucher. Sedangkan, peran yang sering dimainkan dalam online game DOTA 2 adalah peran support.
Tabel 2

Deskriptif Usage Responden (Lanjutan)

\begin{tabular}{|c|c|c|}
\hline Profil & Frekuensi & Persentase (\%) \\
\hline \multicolumn{3}{|l|}{ Alasan bermain } \\
\hline Grafik & 337 & 40,6 \\
\hline Kerja sama teman & 657 & 79,2 \\
\hline Desain permainan & 462 & 55,7 \\
\hline Karakter yang unik & 332 & 40,0 \\
\hline Lainnya & 187 & 22,5 \\
\hline Total & 1.975 & 238,0 \\
\hline \multicolumn{3}{|l|}{ Metode pembayaran } \\
\hline Voucher & 278 & 33,5 \\
\hline Kartu kredit & 95 & 11,4 \\
\hline $\begin{array}{l}\text { Pihak ketiga (forum jual beli, } \\
\text { online shop, teman) }\end{array}$ & 464 & 55,9 \\
\hline $\begin{array}{l}\text { Belum pernah melakukan } \\
\text { pembayaran }\end{array}$ & 129 & 15,5 \\
\hline Total & 966 & 116,3 \\
\hline \multicolumn{3}{|l|}{ Peran online game DOTA 2} \\
\hline Support & 325 & 39,2 \\
\hline Roaming & 168 & 20,2 \\
\hline Midlaner & 245 & 29,5 \\
\hline Tanker & 92 & 11,1 \\
\hline Total & 830 & 100,0 \\
\hline
\end{tabular}

\section{B. Saran}

Saran untuk penelitian selanjutnya dapat meneliti mengenai model bisnis yang ada dalam online game itu sendiri [18]. Penelitian selanjutnya juga dapat meneliti mengenai strategi pemasaran yang diterapkan dalam pemasaran online game [19]. Selain itu, penelitian selanjutnya bisa meneliti mengenai kepuasan terhadap virtual item pada online game [20].

\section{DAFTAR PUSTAKA}

[1] Statista, "Value of the global video games market from 2011 to 2020 (in billion U.S. dollars)," 2015. [Online]. Available: https://www.statista.com/statistics/246888/value-of-the-glo balvideo-game-market/.

[2] J. Brightman, "Mobile to overtake PC in $\$ 99.6$ bn glo bal gam es market - Newzoo," 2016. [Online]. Available: http://www.gamesindustry.biz/articles/2016-04-21 -m obile-to overtake-pc-in-usd99-6bn-global-market-newzoo.

[3] L. Cosseboom, "Indonesia is the fastest growing market for games in Southeast Asia," techinasia, 2015. [Online]. Available: https://www.techinasia.com/indonesia-games-southeast-asianewzoo-study.

[4] D. Mahardy, "Industri game Indonesia hasilkan Rp4,45 triliun di 2015," Techno, 2016. [Online]. Available: http://www.techno.id/tech-news/industri-game-indonesiahasilkan-rp445-triliun-di-2015-160105w.html.

[5] M. Vellanki, "This Is The Current State Of The Video Game Industry," Mahesh-vc, 2016. [Online]. Available: http://www.mahesh-vc.com/blog/this-is-the-current-state-of-thevideo-game-industry.

[6] Steamspy, "Top Steam Games in Indonesia," Steamspy, 2017..

[7] A. Cook, "Four issues shaping the future of video game marketing," Campaignlive, 2013. [Online]. Available: http://www.campaignlive.co.uk/article/four-issues-shapingfut ure-video-game-marketing/1221970.

[8] B.-W. Park and K. C. Lee, "Exploring the value of purchasing online game items," Comput. Human Behav., vol. 27, no. 6, pp 
2178-2185, 2011

[9] K.-L. Hsiao and C.-C. Chen, "What drives in-app purchase intention for mobile games? An examination of perceived value s and loyalty," Electron. Commer. Res. Appl., vol. 16, no. 1, pp. $1-$ $12,2016$.

[10] A. E. Voiskunsky, O. V. Mitina, and A. Avetisova, "Playing online games: Flow experience," Psychol. J., vol. 2, no. 1, p p. 259-281, 2004.

[11] G. Armitage, M. Claypool, and P. Branch, Networking and Online Games. London: Wiley, 2006.

[12] S. Zhu and L. Wang, Online Game Addiction Among University Students. Amsterdam: International Social Work, 2011.

[13] J. Lee, "What Is Dota 2 \& Why Should You Care?," makeuseof.com, 2013. .

[14] M. G. Pratama, B. M. Wibawa, and A. Kunaifi, "Analisis Deskriptif Konsumen Dan Mitra Pengemudi Pada Jasa Transportasi Online Ride Sharing," J. Sains dan Seni ITS, vol. 6, no. 2, pp. 164-167, 2017.

[15] R. O. Putri and B. M. Wibawa, "Identifikasi Permasalahan Komplain pada E-Commerce Menggunakan Metode Fishbone,"
J. Sains dan Seni ITS, vol. 6, no. 1,pp.37-41,2017.

[16] B. H. Ashari, B. M. Wibawa, and S. F. Persada, "Analisis Deskriptif dan Tabulasi Silang pada Konsumen Online sh op di Instagram (Studi Kasus 6 Universitas di Kota Surabaya)," $J$. Sains dan Seni ITS, vol. 6, no. 1,pp.12-16,2017.

[17] G. O. Djaswadi, B. M. Wibawa, and A. Kunaifi, "Analisis Deskriptif dan Tabulasi Silang pada Konsumen Taxi Ride Sharing: Studi Kasus Perusahaan Taxi Ride Sharing," J. Sains dan Seni ITS, vol. 6, no. 2, pp. 246-251,2017.

[18] B. M. Wibawa and I. Baihaqi, "Desain Inovasi Model Bisnis Untuk Pengembangan Bisnis Vaksin HydroVac," in Konferen si Nasional Riset Manajemen VIII, 2014

[19] B. M. Wibawa and M. Aryanto, "Optimalisasi Strategi Pemasaran Lembaga Bimbingan Belajar Bahasa Inggris Menggunakan Metode Education Service Quality,"J. Manaj., vol. 13, no. 1, pp. 21-57,2016.

[20] B. M. Wibawa, I. Vanany, and F. Anggara, "Determinan Kepuasan Pelanggan Pada Produk Pertamina Lubricants," $J$. Bisnis dan Manaj., vol. 7, no. 1, pp. 83-98, 2017. 